\title{
Public Information about Clinical Trials and Research
}

\author{
Yannick Plétan, ${ }^{1}$ Faïez Zannad, ${ }^{2}$ Patrice Jaillon ${ }^{3}$ and the Participants in Round Table No. 1, \\ Giens XVIII ${ }^{\dagger *}$ \\ 1 Pfizer, Paris, France \\ 2 CIC-INSERM-CHU Nancy, France \\ 3 CHU Saint-Antoine, Paris, France
}

\begin{abstract}
Be it to restore the confused image of clinical research in relation to the lay public, or to develop new ways of accruing healthy volunteers or patients for clinical trials, there is a need to draft some guidance on how best to provide information on research. Although the French legal and regulatory armamentarium in this area is essentially liberal, there is currently little-justified reluctance among study sponsors to advertise publicly. A group of academic and pharmaceutical industry researchers, assembled for a workshop, together with regulators, journalists, representatives from ethics committees, social security, patient and health consumer groups and other French institutional bodies, has suggested the following series of recommendations:

- there is no need for additional legal or regulatory constraints;

- sponsors should be aware of and make use of direct public information on trials;

- a 'good practice charter' on public communication about clinical trials should be developed;

- all professionals should be involved in this communication platform;

- communication in the patient's immediate vicinity should be preferred (primary-care physician, local press);

- clinical databases and websites accessible to professionals, but also to patients and non-professionals, should be developed;

- genuine instruction on clinical trials for physicians and health professionals unfamiliar with such trials should be developed and disseminated;

- media groups should receive at least some training in the fundamentals of clinical research.
\end{abstract}

Keywords: information, public, clinical trials, research

Text received May 6, 2003; accepted May 23, 2003

\section{Introduction}

While a panel was holding a meeting in Giens on clinical research, the headlines of a 'general public' health magazine read, partly in red letters: "400 000 French people are lending their bodies for medicine - Who is testing our drugs? - Human guineapigs: selection, remuneration, risks." [1]

In a few words, this is how certain types of media and, as a result, the public generally perceived clinical research in France in 2002. At the same time, a sample of these French clinical researchers, their supervisory authorities and an assembly of representatives of committees protecting these persons were meeting together and asking themselves how specialised publications, the general press and other media might group together to promote the development of clinical research nationally - a recurring cause for concern ${ }^{[2]}$ - while actively helping to recruit patients for our clinical drug trials. A sample of the same group was heard to comment a few weeks earlier, during a meeting on this subject

$\dagger$ For a list of participants, please see the end of the article.

* Articles, analyses and proposals arising from the Giens Clinical Pharmacology Meetings are the responsibility of their authors and do not reflect the views held by their supervisory organisation. 
at the Senate, that the notion of 'human guinea pigs' was happily a thing of the past.

This subject was also discussed at the 10th Meeting of the Association for the Development of Clinical Pharmacology (Association pour le Développement de la Pharmacologie Clinique) in Paris, in October 1997. [3]

\section{The Status of the Problem: Delimitation of the Subject}

The subject, which by definition is extremely vast, was deliberately limited as follows:

- by 'public', we mean patients participating or likely to participate in clinical trials, their close friends and families and, by extension, any person concerned with this subject;

- by 'biomedical research', we mean clinical drug trials;

- together with 'information', we will also consider the 'training' initiatives aimed at the same target audiences;

- by 'media', we mean all potential media support (the press as a whole, websites, posters, specific documents);

- the particular question of information with a view to gaining consent was considered irrelevant;

- nevertheless, information on the subject with regard to the global results of research, as laid down by the law relating to the rights of patients, ${ }^{[4]}$ will be discussed.

\section{Regulatory Framework and Status of the Supervisory Institutions}

The traditional view of sponsors of clinical trials is that information given to the general public with regard to clinical trials is strictly controlled. This view may result from drug manufacturers being prohibited by law to provide information to the general public on their drugs. ${ }^{[5]}$ It may also result from the observation that several institutions organising biomedical research exist in order to ensure that it is conducted in a relevant and ethical manner. But, in fact, in France, there is no specific legal or regulatory framework concerning campaigns to recruit patients by poster advertising, the press, radio, or the Internet.

The European Clinical Trials Directive, ${ }^{[6]}$ whose transposition into national law was expected in May 2003, requires, in article 6-k, that the terms of recruitment be communicated to an ethical committee, i.e. in France to a Committee for the Protection of Persons Participating in Biomedical Research (Comité Consultatif de Protection des Personnes dans la Recherche Biomédicale [CCPPRB]).

The following information is derived essentially from individual experiments of sponsors that are described later in the text.
A non-public opinion drawn up by the National Consultative Committee on Ethics (Comité Consultatif National d'Ethique [CCNE], unpublished data) in April 2001, in response to a written question, stresses the ethical nature of the message to be used its simple, factual character relating to the benefits and the risks associated with the research as well as its terms, but omitting the mention of any indemnification. The CCNE also sets out the roles of the CCPPRB and the National Committee for Information and Freedom (Commission Nationale de l'Informatique et des Libertés [CNIL]) with regard to clinical trials. At the same time, an opinion of the National Order of Physicians (Conseil National de l'Ordre des Médecins [CNOM]) dated December 2001 (Laboratoire 3M, unpublished data) differentiates between trials without any direct individual benefits (DIB) [promotion of such trials is on the whole permitted], and with DIB (more restrictive, with the necessity of involving the family doctor), and insists on the importance of the investigator informing the family doctor of the trial in which his/her patient is involved.

The French agency for the sanitary safety of health products (Afssaps [Agence française de sécurité sanitaire des produits de santé]), which has been consulted in this regard, considers that it is not up to the Advertising Committee (Commission de la Publicité ) to express an opinion on the clinical trials, nor is it the role of the Clinical Trials Unit (Unité Essais Cliniques), in general, to express an opinion systematically on the recruitment procedures for the trials. On the other hand, this unit could address any relevant issue in this regard.

Following France's example, other European countries do not have any legal frameworks with regard to information concerning clinical trials. Very little common practice exists on this subject, except in Scandinavia and The Netherlands, where this practice is growing. However, on 3 October, 2002, the Environmental Committee of the European Parliament voted against the European Commission project concerning communication with the general public regarding certain drugs (for asthma, AIDS, diabetes) for a trial period of 5 years. Even though this has no direct bearing on our approach, this vote indicates the limits that European institutions see regarding the subject of information. In the US, communication of information on trials is unrestricted, subject to the approval of the Institutional Review Boards (IRBs) according to the principle that information on a trial is authorised if the trial itself is authorised. This principle of transparency is in agreement with section 113 of the Modernisation Act of the US FDA, ${ }^{[7]}$ and has been adopted by the Pharmaceutical Research and Manufacturers of America (PhRMA), representing the US pharmaceutical industry. ${ }^{[8]}$ A US FDA website aims to make this information available to the public, unless this is expressly and justifiably opposed by the sponsor. 
In Japan, since June 1999, similar rules have been enforced, but the name of the product cannot be mentioned, which in no way prevents massive advertising advocating clinical trials and active recruitment, in particular through websites.

\section{Recommendations of the Panel with Regard to the Regulatory Framework}

All participants, each of whom represents a different point of view, agreed that the development of specific legislation should in principle be opposed.

Even though there exists a consensus regarding the principle that the methods of communication to be used should be submitted to the CCPPRB with the global file for its opinion, it was not deemed necessary to seek a prior and specific opinion from the CCPPRB on the information documents themselves.

It should be noted that the clinical trials directive - presently being drawn up - and relating to the global file to be presented to the CCPPRB, provides for the filing of procedures and documents.

It should also be noted that the following comments and proposals have been made by the group:

- there is a reluctance to distinguish between trials with or without DIB (because of the discriminatory nature of such a distinction and because of the distortion involved in a comparison of the risks/benefits between the two methods);

- it is proposed that a 'good practice charter' be established (considering a code of ethics, credibility, intelligibility, absence of any possible confusion with advertising for a drug or a company, and how to use call centres).

One matter is, however, still unresolved: should the amount of indemnification of patients be mentioned (for the sake of transparency) or remain undisclosed (to avoid linking a mercenary aspect with the situation).

\section{What is the Demand with Regard to Information?}

This question is central to understanding the problem and precedes making any recommendations. In order to define the answer to this question, a survey approach was used.

Various surveys were conducted:

- a survey conducted with a small sample of consumers;

- a survey conducted with patients from the investigator/doctors' clientele (table I);

- a survey conducted with general practitioners carrying out clinical trials (table II);

- a survey of nurses in two university hospitals (CHUs) [table III];

- a survey of parents of children seen in hospital.

The results are as follows:
1. Trials using human participants are considered a necessity ( $90 \%$ of patients) [from a survey conducted with patients of research doctors; Giacomino A, unpublished data]; to take part is a good thing (73\% of the general public); ${ }^{[9]}$ and those trials carried out in connection with doctors who have their own practices are necessary ( $89 \%$ of investigator/doctors with their own practices) [from a survey conducted with a group of research doctors; Giacomino A, unpublished data].

2. Motivation to participate in clinical trials varies according to the situation: only $12 \%$ of parents of children would agree to their children taking part in a clinical trial; ${ }^{[10]} 72 \%$ of investiga-

Table I. Patients' opinions with regard to therapeutic trials. Questionnaires distributed at random in the waiting rooms of investigator/doctors (78 usable responses) ${ }^{\mathrm{a}}$

\begin{tabular}{|c|c|}
\hline Question & Positive responses \\
\hline $\begin{array}{l}\text { 1. Have you already taken part in research } \\
\text { for a therapeutic trial? }\end{array}$ & $12.8 \%$ \\
\hline $\begin{array}{l}\text { 2. Were you satisfied with your } \\
\text { participation? }\end{array}$ & $11.1 \%$ \\
\hline $\begin{array}{l}\text { 3. Did someone already suggest that you } \\
\text { participate? }\end{array}$ & $14.1 \%$ \\
\hline $\begin{array}{l}\text { 4. If your doctor suggested that you } \\
\text { participate, would you agree? }\end{array}$ & $72.0 \%$ \\
\hline \multicolumn{2}{|l|}{$\begin{array}{l}\text { 5. Has anyone in your immediate circle } \\
\text { of relations/friends taken part in a } \\
\text { clinical drugs trial? }\end{array}$} \\
\hline yes & $11.8 \%$ \\
\hline no & $68.0 \%$ \\
\hline don't know & $19.7 \%$ \\
\hline \multicolumn{2}{|l|}{$\begin{array}{l}\text { 6. Do you feel that the information } \\
\text { which you have on clinical trials is: }\end{array}$} \\
\hline good & $19.2 \%$ \\
\hline average & $23.0 \%$ \\
\hline bad & $57.7 \%$ \\
\hline \multicolumn{2}{|l|}{$\begin{array}{l}\text { 7. Do you think that clinical and therapeutic } \\
\text { trials on willing human beings are } \\
\text { necessary? }\end{array}$} \\
\hline yes & $89.7 \%$ \\
\hline no & $0.0 \%$ \\
\hline no answer & $11.3 \%$ \\
\hline $\begin{array}{l}\text { 8. Would you like more information on } \\
\text { clinical trials? }\end{array}$ & $85.7 \%$ \\
\hline \multicolumn{2}{|l|}{$\begin{array}{l}\text { 9. By what means? (by decreasing order of } \\
\text { priority) }\end{array}$} \\
\hline & 1. Doctor \\
\hline & 2. Newspapers \\
\hline & 3. TV (place equal with 2) \\
\hline & 4. Radio \\
\hline & 5. Internet \\
\hline \multicolumn{2}{|c|}{$\begin{array}{l}\text { Supplementary document with patients' comments and an analysis, } \\
\text { with permission. From a survey conducted with patients of research } \\
\text { doctors; Giacomino A, unpublished data. }\end{array}$} \\
\hline
\end{tabular}


Table II. Opinion of investigator/doctors. Questionnaire sent by e-mail to 30 doctors (26 usable responses) ${ }^{\mathrm{a}}$

\begin{tabular}{|c|c|c|}
\hline Question & Positive response & No response or negative response \\
\hline 1. Do you conduct clinical trials? & 23 & 3 \\
\hline 2. Have you received proposals to conduct trials? & 25 & 1 \\
\hline 3. Do you wish to conduct trials? & 21 & 5 \\
\hline 4. Are you satisfied with your participation in clinical trials? & 21 & 2 \\
\hline 5. Were your patients satisfied with their participation? & 23 & \\
\hline 6. Is your information on the clinical trials: & & 0 \\
\hline bad & 16 & \\
\hline average & 6 & \\
\hline good & 4 & \\
\hline $\begin{array}{l}\text { 7. Do you think that it is necessary to conduct clinical trials in the field of } \\
\text { general medicine? }\end{array}$ & 23 & 3 \\
\hline \multicolumn{3}{|l|}{$\begin{array}{l}\text { 8. Difficulties encountered (by decreasing order of importance on the scale } \\
0 \text { to } 10 \text { [average responses]): }\end{array}$} \\
\hline lack of time & 8.1 & \\
\hline methodology & 6.0 & \\
\hline money & 3.6 & \\
\hline laboratory & 4.4 & \\
\hline patient & 5.6 & \\
\hline patient's entourage & 3.9 & \\
\hline other & 6.0 & \\
\hline 9. Do you wish to receive more information on clinical trials? & 13 & 13 \\
\hline \multicolumn{3}{|l|}{ 10. Preferred means of information (in decreasing order): } \\
\hline & 1. Internet & \\
\hline & 2. CME evening session & \\
\hline & 3. Training over 2 days & \\
\hline & 4. University diploma & \\
\hline & 5. Medical journals & \\
\hline 11. Do you wish to relay information to your patients? & 17 & 9 \\
\hline
\end{tabular}

a Supplementary document with doctors' comments and an analysis, with permission. From a survey conducted with a group of research doctors; Giacomino A, unpublished data.

CME = continuing medical education .

tor/doctors' patients (from a survey of patients of research doctors; Giacomino A, unpublished data) would be willing to participate ( $13 \%$ had already taken part in trials $\left.{ }^{[9]}\right)$; and $25 \%$ of ordinary adults would take part (actual participation rate is $4 \%$ ). In other words, when 'proximity' information is absent, such as from a person belonging to a circle of close family/friends or a family doctor who is himself involved in the trials, the level of motivation is low.

3. Nurses' knowledge of the framework of clinical trials is extremely limited (from a survey conducted at the University Hospital of Tours; Autret-Leca E, unpublished data). Although $90 \%$ of nurses working in teaching hospitals, and therefore in contact with investigator/doctors and patients included in clinical trials, know that legislation exists with regard to clinical trials, $45 \%$ do not know that study protocols are submitted to a CCPPRB, ${ }^{[11]}$ and $36 \%$ only know that the Committee's opinion must be sought prior to conducting the trial.
4. Only $19 \%$ of patients of the investigator's clientele consider that the information on clinical trials is good and $86 \%$ would like more information (from a survey conducted with patients of research doctors; Giacomino A, unpublished data).

5. Some people are suspicious of information relating to trials, particularly if this comes from a sole source, all the more so if this is industrial (from an opinion poll; Padioleau MF, unpublished data).

6. Preference is given to 'proximity' information (family doctor, press) [a survey conducted with patients of research doctors; Giacomino A, unpublished data].

7. Intelligibility is a necessary condition. A 'translator' is often necessary.

8. The motivation of investigators (from a survey conducted with a group of research doctors; Giacomino A, unpublished data) is linked to the time needed for the trial and its methodology.

9. Fifty percent of investigators would like to be better trained/informed with regard to trials, the preferred methods 
being the internet (self-training), continuing medical education, and consecutive 2-day training sessions.

\section{Messages and Targets}

Two types of messages may be considered: those messages relating to clinical research in general and those relating to a particular trial.

\section{1 Information on Trials in General}

Targets of information on trials in general are as follows: the general public; general as well as specialised publications; doctors (whether investigators or not); other health professionals (chemists, nurses, other public or private health managers); students; and schoolchildren.
The group members (from institutions, the pharmaceutical industry, consumers, patients, the press) have agreed on the following recommendations:

- $\quad$ provide information, or training, on a regular basis, and not during a critical and therefore emotionally charged situation - such situations often result in major headlines in the general press;

- develop the notion of a 'partner' citizen and insist on altruism, a necessary requirement for research to progress even if the participant's direct interest is not always obvious;

- explain that trials are 'necessary' and that their results contribute to the improvement of health, in every sense of the word - i.e. they contribute, for example, to the development of medical practices, the elaboration of public health recommendations and the therapeutic management of patients by their family doctors, and to the training of students.

Table III. Test of degree of knowledge carried out at the University Hospital of Tours with 19 nurses from this hospital and 51 doctors with their own practices in the central region ${ }^{\mathrm{a}}$

\begin{tabular}{|c|c|c|}
\hline Question & $\begin{array}{l}\text { Nurses } \\
(\%)\end{array}$ & $\begin{array}{l}\text { Doctors with their own practices } \\
(\%)\end{array}$ \\
\hline \multicolumn{3}{|l|}{ 1. Does legislation exist on biomedical research in France? } \\
\hline yes & 90.0 & 90.0 \\
\hline no & 0.0 & 2.0 \\
\hline don’t know & 10.0 & 8.0 \\
\hline \multicolumn{3}{|l|}{ 2. Can a doctor make a patient take part without his/her knowledge? } \\
\hline yes & 5.0 & 4.0 \\
\hline no & 95.0 & 90.0 \\
\hline don't know & 0.0 & 6.0 \\
\hline \multicolumn{3}{|l|}{ 3. CCPPRB: } \\
\hline is an ethics committee responding to patients during the study (yes)? & 31.0 & 20.0 \\
\hline is a committee ruling on the protection of persons prior to the beginning of a study (yes)? & 36.0 & 60.0 \\
\hline don’t know & 32.0 & 20.0 \\
\hline \multicolumn{3}{|l|}{$\begin{array}{l}\text { 4. Only the authorisation of one parent is required to include a child } \\
\text { in a trial? }\end{array}$} \\
\hline yes & 11.0 & 8.0 \\
\hline no & 79.0 & 55.0 \\
\hline don’t know & 0.0 & 37.0 \\
\hline \multicolumn{3}{|l|}{ 5. All biomedical research is declared to the authorities (DGS, Afssaps)? } \\
\hline yes & 74.0 & 61.0 \\
\hline no & 5.0 & 14.0 \\
\hline don’t know & 21.0 & 25.0 \\
\hline \multicolumn{3}{|l|}{ 6. Prior to being put on the market, a molecule must be tested on: } \\
\hline animals only & 0.0 & 0.0 \\
\hline animals and humans & 100.0 & 100.0 \\
\hline humans only & 0.0 & 0.0 \\
\hline don’t know & 0.0 & 0.0 \\
\hline
\end{tabular}

a From a survey conducted at the University Hospital of Tours; Autret-Leca E, unpublished data. With permission.

Afssaps $=$ French agency for the sanitary safety of health products (Agence française de sécurité sanitaire des produits de santé); CCPPRB = Committee for the Protection of Persons Participating in Biomedical Research (Comité Consultatif de Protection des Personnes dans la Recherche Biomédicale); DGS = General Health Directorate (Direction Générale de la Santé). 


\subsection{Information on One Trial in Particular}

The targets of information on a specific trial are the investigator, the family doctor, the patient and, if necessary, his/her close family/friends. Recommendations are listed below:

- The patient must be treated as a responsible individual, in charge of his/her own health and with freedom of choice.

- Complete care of the person agreeing to take part in the clinical trial must be ensured - i.e. from his/her 'initial' welcome into the structure that has recruited him, during the entire length of the medical follow-up, and until the results are presented. The absence of continuity and respect for the individual during care undoubtedly explains why people refuse to enter clinical trials and prevents the patient from giving any 'positive' publicity regarding the particular trial (or on clinical research in general) to his/her immediate circle.

- The information provided must involve the whole chain of nursing staff caring for the patient, and not only his/her contact person in charge of clinical trials. We should remember that it is very rare that the patient's family doctor is the investigator, even though the doctor has been informed and consents to the research on behalf of his/her patient. The doctor's 'actual experience' and that of the other nursing staff may be a determining factor in his/her level of trust and wish to see the patient 'shared' between care and research activities and, therefore, between the investigator/doctor and the family doctor.

\section{What Information Is Required?}

\subsection{Improving Recruitment}

Information aimed at improving recruitment is one requirement. With regard to this type of information, the results of two additional experiments have been reported.

\subsubsection{The ' $3 M$ ' Experiment}

This experiment involved the development of an information platform (number of a call centre, a website dedicated to the trial) targeted to the general public on a current trial on genital herpes. This multicentre and multinational ambulatory trial experienced some difficulty in recruiting participants, particularly in France. The platform consisted of an advertisement in the press (figure 1).

The development of this experiment enabled its sponsor to receive the opinions of different supervisory institutions (these 'opinions' are summarised in section 3) and, above all, released it from any prerequisites, thus avoiding confusion between research and pharmaceutical advertising. Therefore, there was no requirement to mention the name of the treatment under trial, the

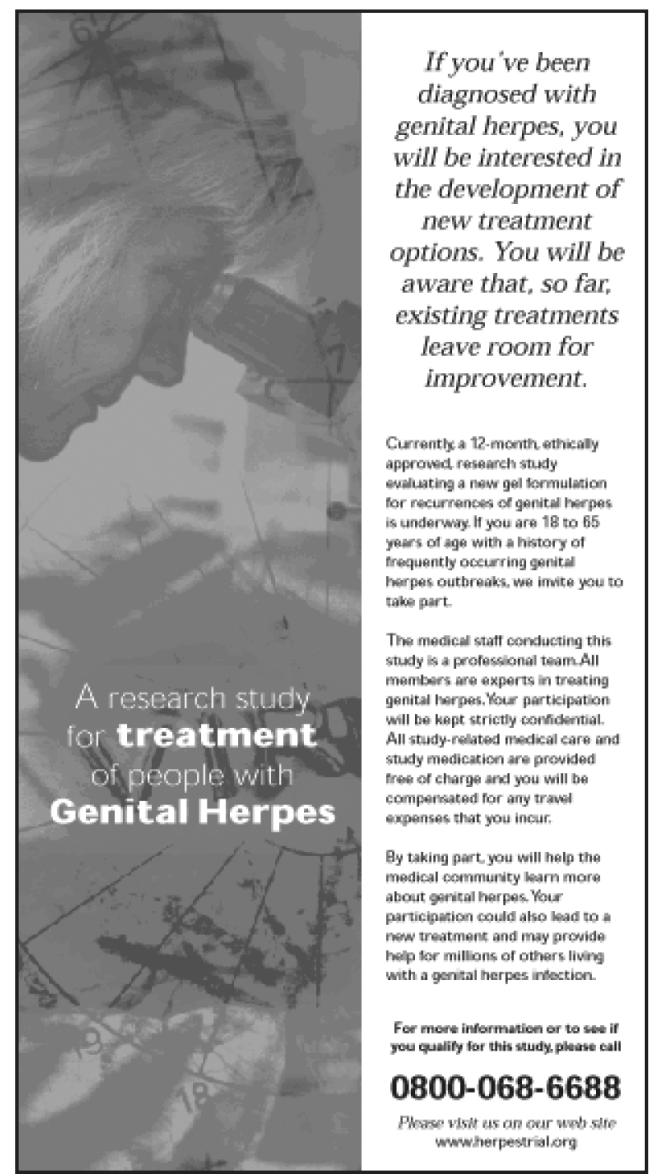

Fig. 1. Recruitment campaign conducted by means of an advertisement in the press (adapted from a 3M Laboratoires' document, with permission).

name of the sponsor (this omission was debatable for some) and the identity of the patient. On the other hand, the disease concerned, the nature of the clinical trial, and the mechanism of action of the treatment being tested were required to be clearly explained.

This experiment, repeated during a subsequent trial, resulted in a gain with regard to recruitment time ( 3 months for the trial) and the date of filing the marketing authorisation dossier (3 months also). However, this was at a considerable cost per patient, potentially compensated for by an increase in the operating period of the ultimate marketing plan.

\subsubsection{The Approach of the Clinical Research Centre of the University Hospital of Nancy}

The option chosen was a series of advertisements in the local press describing the disease and the type of patients sought. These patients were invited to contact the nurses of the Clinical Research Centre of the University Hospital of Nancy (Nancy CIC), who were properly informed regarding the trial and who were 
involved in setting up a 'call centre' for the trial. The result was that recruitment was made considerably easier and at a modest cost (for the advertisements and personnel).

The question remains whether to extend these experiments to all trials.

Four points were raised in the discussion, overall in favour of the general application of the experiment:

- Sponsors in Europe, and in particular in France, would be inhibited more by preconceived ideas than by the restrictions of such a framework. It is necessary to fearlessly 'take the plunge', and undertake this type of manoeuvre more widely, while measuring the advantages on a case-by-case basis.

- Any change in recruitment procedures is vulnerable to bias - such as 'professionalising' certain patients or obtaining an over-representation of specific subsets. We must guard against this on a case-by-case basis.

- The use of a 'call centre' seems to be a useful practice, in that it professionalises the welcome and protects the sponsor and the patient.

- Patient associations may also be reliable intermediaries and play the same role as a call centre, independently of the sponsor. They must not, however, prevent the sponsor from providing direct information, if so requested.

\subsection{Informing the Patient at the End of the Trial}

Informing the patient of the trial results is another requirement. The law of 4 March, $2002^{[4]}$ provides that "... the person .... IS informed of the GLOBAL results...". The CCPPRB recommends that, from now on, this provision is included in the information leaflet given to the patient and accompanying the consent form.

Although positive notions have emerged from the discussion, some difficulties have arisen.

- As regards the positive points, the communication of results is one of the possible components involved in recruiting patients, not so much for the completed trial but for subsequent trials, i.e. the possibility of a 'halo' effect vis-à-vis other potential patients. This obligation to the patient would furthermore remind the sponsor not to forget to inform the investigators of the global results of the trial.

- Among the difficulties, we have noted the following: negative trials (particularly where the placebo has been more effective or better tolerated than the trial product), which raises the question of whether or not to insist on 'loss of luck' for the patients included; very long trials, where a considerable period can elapse between the withdrawal of the patient from the study and study completion - and, ultimately, the analy- sis of the study; finally, confidentiality problems for the sponsor of the trial, not so much for reasons of intellectual or competitive property as for the embargoes relating to communication and publication in the international media, which operate according to strict rules.

- The suggestion is to release this information as soon as it becomes available on a website accessible to the patient (section 8.2 and table IV).

\section{Information Vectors}

\section{1 Health Professionals}

Health professionals are the best communicators with regard to trials.

They include investigator/doctors, but also family doctors, who would use their training and motivation in this domain. A preliminary medical training session in clinical research, including the critical reading of articles as well as in-house training in clinical research within the conventional framework (Caisse Nationale d'Assurance Maladie [CNAM] $)^{[12]}$ are essential factors in enabling family doctors to participate in providing information to their patients. Information by this means involves all stages of the trial, the patient and the people in his/her immediate circle, and the family doctor, if he/she is not the investigator. Article 59-61 of the law of 4 March $2002^{[4]}$ makes it obligatory for doctors to undergo training. If the doctor's practice includes clinical trials, the direct application should be to include clinical research in the field of this obligation.

The dispensing chemist is important in that he/she is often the first and last provider of information to the patient. Unfortu-

Table IV. Websites associated with clinical trials

1. Cancer.gov: http://www.cancer.gov/

2. CenterWatch.com: http://www.centerwatch.com/

3. Search the studies: http://clinicalstudies.info.nih.gov/

4. ClincalTrials.gov: http://clinicaltrials.gov

5. Clinical Studies: http://www.nei.nih.gov/neitrials/index.htm

6. TrialsCentral: http://www.trialscentral.org

7. Current Controlled Trials: http://www.controlled-trials.com/

8. Actis: http://actis.org/index.html

9. ClinicalTrials.com: http://www.clinicaltrials.com/trials/trials.asp

10. Réseau canadien sur les essais cliniques:

http://www.hivnet.ucb.ca/list1fFrame.html

11. Essais européens: http://www.curatrials.com/

12. FNCLCC: http://www.fnclcc.fr/-sci/bect/clcc/clcc.htm

13. Arcat SIDA: http://www.arcat-sida.org/essais/content.html

14. INSERM: http://birbpi.inserm.fr:8001

http://onyx.tolbiac.inserm.fr/ (puis consultation/protocoles)

15. Afssaps: http://afssaps.sante.fr/htm/5/repec/repec0.htm 
nately, the chemist, of all the participants in the chain, is probably the person with the least amount of information on the progress of trials, and does not even know where to obtain information if patients request it. Informing chemists would at least ensure that they did not hold up the progress of trials.

\subsection{Registries}

Registries are highly developed in the US, but limited to a few initiatives in France. They can provide general information on clinical trials or on trials concerned with a specific disease (cancer, AIDS, rare diseases). For a given trial, they can fill a dual role in providing information on its existence, its status, terms of participation, investigators or centres that can be contacted, and, sometimes, provide general information on results if the study has been completed. They may be set up by universities, or be institutional or government websites or those of companies specialising in recruitment.

A list of the best known websites, with their addresses, are shown in table IV.

Among these websites, which provide among other things general information on clinical trials with the aim of responding to the question 'what is a clinical trial?', we can name the 'Canadian Health Network', the 'Clinical Trial Program' of the University of Indiana, 'Clinical Trial Information for Patients', 'CenterWatch' and 'ClinicalTrials.gov'. This last site is without doubt the best known, with more than 6000 trials conducted by public and private institutions throughout the world. Among the sites associated with a disease, 'Cancer.gov' presents more than 1700 trials with a patients' version and a health professionals' version. In France, there are several websites set up by either university centres or patient associations (cancer, AIDS etc.). Some sites aim to be mainly trial repositories directed at health professionals. Examples are 'Current Controlled Trials', a medium of the Cochrane Centre and the Medical Research Council in Great Britain, with a record of more than 14000 trials registered and classified; and the site where INSERM has put online a data bank of 100 clinical and epidemiological trials in hepatitis B and C. However, we should note above all the recent initiative of Afssaps, which, in October 2002, put an index of clinical trials on its internet site (see table IV). This mainly concerns trials undertaken on the treatment of rare diseases and hepatitis (figure 2).

Nevertheless, even though this approach is growing, it still encounters the refusal of certain sponsors to reveal their study plans and, above all, to make their results available to the general public. Certain approaches and initiatives tend today to overcome these difficulties.

\subsection{Media Support Available to Researchers}

Among the elements that can be made available to investigators to help them in their mission to inform are brochures on clinical research in general or on specific topics (e.g. diabetes), and posters for the waiting room (Nancy $\mathrm{CIC}^{[13]}$ ).

In addition to the preliminary and in-house training described above, meetings on a specific theme enable the doctorpatient relationship to be examined more closely in a research situation, e.g. using role play to help the physician 'switch' to the most appropriate behaviour depending on the situation (care or research). The most sophisticated post-graduate courses would be necessary to understand certain methodologies. These sometimes need to be simplified in order to explain them to the patient - an example being methodologies relating to morbidity-mortality studies, which pose certain obvious problems of communication.

An important support, which must not be neglected by the sponsor, is to provide information during the trial on the progress of the study, on all the types of problems encountered by other investigators and their solutions, and information at the end of the trial. This information is linked to the legal obligation stipulated in the law of 4 March $2002 .{ }^{[4]}$ Training to deliver this information, which is sensitive information in terms of the patients and, under certain circumstances, their families is, undoubtedly, to be provided also. The call centres themselves can extend the range of their services and provide useful media support for investigators (table $\mathrm{V})$.

\subsection{The Media}

Activity in relation to the media should not only be to inform them, so that they in turn disseminate this information in their columns, but also to 'train' them, i.e. provide them with the elements that would permit them to grasp all the problems associated with trials and demystify certain elements (remuneration of healthy volunteers, researchers' fees, selection of subjects, choice of certain trial populations etc.). It has been suggested that the Association of Medical Journalists (Association des Journalistes Médicaux [AJMED]), which comprises approximately 75 journalists from the specialised medical press, be the platform for this experiment.

Nowadays, it has been observed that the media enjoy ' 2 speed' information, depending on whether journalists are associated with medical publications or those aimed at the general public. The information relayed by the latter is always limited and articles are often inconsistent. As a result, journalists turn to their personal contacts in order to 'decode' useful information - with all the dangers such choices involve. 


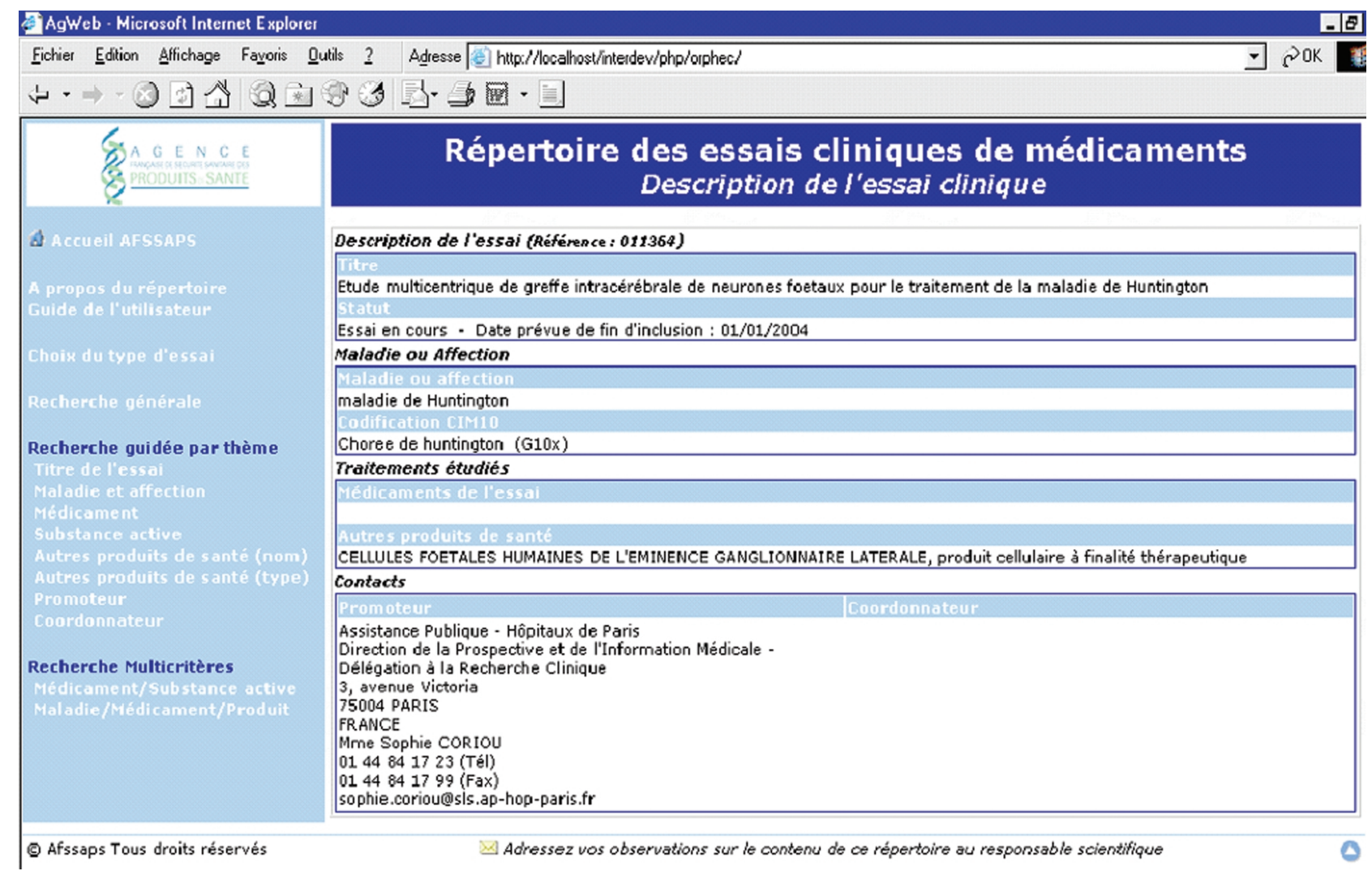

Fig. 2. Afssaps Internet site: an index of clinical trials. Afssaps = French agency for the sanitary safety of health products (Agence française de sécurité sanitaire des produits de santé).

It will be difficult to escape completely from the sometimes obtrusive comments and visible headings of column chiefs, who are motivated purely by commercial considerations. It is necessary to provide 'truer' information, i.e. not only on 'interesting stories' relating to clinical research, but also on its daily routine, its difficulties and its failures, which could change the impressions of the public. At the same time, enhancing the 'practical' aspects' (how to participate, how a trial is run, what becomes of treatment for an ongoing ailment, where to find information, how will my doctor know that I am taking part, will he/she have something to say about it, what am I committing myself to, and what are my rights, etc.) - which are of interest to the reading public - would assist participation in trials.

\section{Discussion and Conclusions}

Most of the subjects under discussion were raised during the workshop meeting and certain points had already been introduced. Some concern basic legal and ethical questions, others relate to practical aspects and question the effectiveness of recruitment campaigns.
Among the legal questions, we are obliged to observe the discomfort of the workshop participants, despite their expertise, with regard to the lawfulness of resorting to recruitment campaigns. Institutional bodies find it difficult to position their opinion and their role in this regard. It is possible that the transposition into French law of the European Directive on Clinical Trials ${ }^{[6]}$ would make it possible to reply to some of these questions. A central point of our debate was resorting to a 'call centre', whose true independence, however well sought after, is debatable and whose functioning makes it necessary to examine the question of medical confidentiality. The Code of Ethics stipulates that the patient cannot release the doctor, to whom he/she confides personal medical information, from the doctor's obligation to confidentiality in relation to third parties, apart from the following: exceptions provided by law in connection with judicial investigations, and the recent exception with regard to the extension to other healthcare workers involved in the patient's treatment, in accordance with the above-mentioned law dated 4 March 2002. ${ }^{[4]}$ Nevertheless, nothing seems to prevent the patient, like all citizens, from confiding any information concerning him/her to third parties on condition that he/she does so of his/her own accord, 
Table V. Services offered by a private call centre and a logistics help centre for the studies (modified from Pro-Clinica data [Centre de Contacts et d'Assistance Logistique Médicalisé pour les Études] ${ }^{[14]}$ )

\begin{tabular}{ll}
\hline Media & Services \\
\hline Permanent telephone & Transmittal of information on clinical \\
assistance & trials: multilingual \\
Interactive voice service & Inclusion: randomisation advice \\
Internet & Preselection telephone questionnaire \\
& Management of appointments: \\
& reminders \\
& Sending of treatments, equipment, \\
& samples \\
& Help with providing data: auto-journal \\
& (patient); CRF (doctor) \\
& Start of interventions \\
& Management of follow-up tables \\
\hline CRF $=$ case report form &
\end{tabular}

CRF $=$ case report form

and that he/she is protected by the French Freedom of Information and Civil liberties Act (Loi Informatique et Libertés) ${ }^{[15,16]}$ if this information is subject to computerised use. This is the situation with regard to the 'call centre' and, indeed, is usually the case. In accordance with the terms of the Act, this 'call centre' must stipulate the rights of the person whom it contacts and request all necessary authorisation. For some lawyers, however, it would be prudent to 'materialise' the consent of the patient with regard to the collection of personal information by confirming this agreement in a written, signed document, stipulating, among other things, that contact was made by the patient (no possible canvassing). ${ }^{[14]}$ Table $\mathrm{V}$ indicates the services that call centres can offer at the present time.

One of the basic questions concerns understanding why the patients' percentages differ, whether the issue is their interest in clinical research, their thoughts regarding participation and finally their actual involvement, regardless of the survey being considered. The gap is small between the first two responses and demonstrates the altruism existing in each of us, once the situation has been explained. Attrition is, in fact, situated around participation. The survey conducted at Saint-Etienne showed that the general public's perception of risk played a central role (from a survey conducted with a group of research doctors; Giacomino A, unpublished data). Let us not forget that the revision of the Helsinki Declaration in $2000^{[17]}$ went as far as to question indirectly the lawfulness of clinical research, in its initial version, by opposing the undertaking of certain trials (in particular, versus placebo when treatment is available) without which any real knowledge is impossible. The publicity created with regard to respecting the right to a therapeutic alternative in certain serious ailments may add to these perceptions. ${ }^{[18]}$ We must admit that there is a paradox that clinical research must control: does not the fact that we conduct clinical trials on human beings demonstrate our need for knowledge and, therefore, our ignorance with regard to the effects of treatments? And attempting to find zero risk with regard to a drug sold to a mass market surely implies, in return, that we must continue to increase the number of patients 'exposed' to research on the drug and, therefore, the probability of observing problems linked to tolerance? Today's 'megatrials' involve more than 20000 patients in order to elucidate benefits, the magnitude of which might appear marginal to some. These trials are, nevertheless, a necessary course to gain knowledge for anyone who wishes to undertake a clear health policy. At the same time, the echoes regarding the 'precautionary principle' transform this into a principle of abstention, i.e. it worries people as much as it reassures them. As a result, the extent of the regulatory precaution taken in trials might reassure certain people but prove to others the potential danger in trials. The ambivalence of this situation plays a rather inhibitory role. On the contrary, when the risks are explained to the patient who is ready to participate in a clinical trial, this rarely ends in his/her refusal, any more than the signature of consent does. This ambivalence relates more to a background perception of persons who have not yet participated in trials. One of the missions of communication to the general public is to reassure. The confidentiality of sensitive and personal information, and more recently confidentiality with regard to property and access to certain databases may be an inhibitory factor. The press has widely echoed these questions with regard to information on the human genome and the phenotyping of entire populations. Discussions are taking place on the ownership and the exploitation of genomic and proteomic factors. ${ }^{[19]}$ Even though the individual impact is still at a virtual stage in most cases, the more general idea that clinical research could in fact unknowingly reveal all information, thus touching the genetic sanctuary of an individual, worries many.

The effectiveness of recruitment campaigns was the basis of these discussions. Nevertheless, the examples presented offered individual proof of effectiveness. The first point is the possible link between general information on the trials and participation in the trials. In other words, will the launching of information campaigns, the training of the media and professionals ultimately change the rate of participation in trials? And the second question is 'will this effect, if it is observed, be maintained in the future?' A first element of the response emanates from the surveys conducted for the workgroup. We have observed that there exists a gradient of interest of 1-3 depending on the proximity or nonproximity of the patient to a source of relevant information (family doctor, investigator, people in his/her immediate circle): $25-75 \%$ for information and $4-12 \%$ for participation. This gra- 
dient seems also to imply a link between information and participation.

Nevertheless, the efforts made by the health authorities to inform patients on the trials have resulted in a participation rate of only 3\% (Assistance Publique - Hôpitaux de Paris, unpublished data), i.e. at best, the rate observed spontaneously. It is possible that there are other disincentives that would explain these characteristics: among them, the difference that might exist between personalised and humanised information (the doctor, the people close to the patient) and disembodied information (booklet, note, TV advertising, press release). A recent enquiry undertaken in the US ${ }^{[20]}$ shows that, as far as medical information is concerned, $61 \%$ of adult Americans trust their doctors, 35\% a nurse, $26 \%$ the internet, $14 \%$ television, and $13 \%$ and $12 \%$, respectively, magazines and newspapers. These data are in agreement with ours, except perhaps for the press, which is placed higher than other media, especially the local press. Here again, we find a notion of proximity. With regard to the effect of information campaigns being maintained in the future, it is interesting to return to the example of the US where the practice has existed for several years. According to a recent survey ${ }^{[21]}$ concerning perception with regard to clinical trials, the percentage of persons who are definitely or probably interested in participating in a clinical trial decreased from 35\% to $31 \%$ between 1998 and 2002. At the same time and paradoxically, the public's knowledge of trials, according to the same survey, increased from $41 \%$ to $55 \%$. When we examine the actual rate of participation in trials, it remained stable at $4 \%$ for that same period. We should, therefore, question (i) the possible relationship between general knowledge regarding the trials and the desire to participate and (ii) the ultimate effectiveness of recruitment, since this is low and apparently indifferent to swings in opinion. This leads us to question whether there exists, on the one hand, global knowledge with no direct link to personal motivation and, on the other hand, motivation that is directly stimulated as soon as the patient is involved or knows that he/she may be involved personally. Therefore, whether or not we should reserve general information for correcting false ideas and present it so that the public receives more specific information at some time, or, conversely, use campaigns for the recruitment of the persons concerned, by the most appropriate means in the proximity of these persons .

To conclude, the workgroup finally set forth a certain number of recommendations, summarised as follows:

- do not create new regulatory restrictions;

- sponsors must not hesitate to use direct information with regard to the general public;

- draw up a professional good practice charter with regard to public information;
- involve the entire chain of professionals in communication activities;

- give greater importance to 'proximity' information (family doctor and local press, as a priority);

- encourage the development of websites and clinical trial databases;

- develop proper training for non-professionals in the clinical trial;

- educate the media on the basics of clinical research.

\section{Participants}

E.Autret-Leca (Hôpital Bretonneau, Tours), Ch. Belorgey (Afssaps, Saint-Denis), M. Bernard-Harlaut (CNAFAL, Paris), D. Cellier (MerckLipha, Lyon), F. Chazelle (MSD, Paris), M.F. Chevallier-Le Guyader (INSERM, Paris), M. Couderc (Sanofi-Synthélabo, Le Plessis-Robinson), D. Debiais (AMGEN, Neuilly-sur-Seine), J. D'Enfert (Aventis, Paris), A.M. Duguet (CCPPRB Toulouse 2, Toulouse), L. Fleury (Afssaps, Saint-Denis), M. Gallard (LEEM, Paris), A. Giacomino (MG France, Avoine), Y. Juillet (LEEM, Paris), H. Kolsky (3M Santé, Cergy-Pontoise), J.P. Lehner (SanofiSynthélabo, Le Plessis-Robinson), F. Lemaire (CHU Mondor, Créteil), M.F. Padioleau (AJMED, Paris), M. Peschanski (INSERM U421, Créteil), S. Ravoire (Lilly France, Saint-Cloud), J.P. Reynier (Faculté de Pharmacie, Marseille), Ph. Ricordeau (CNAMTS, Paris), P. Sassano (Novartis, RueilMalmaison), C. Sibenaler (LEEM, Paris), M.C. Simon (ANRS, Paris), J. Soletti (LEEM, Paris).

\section{References}

1. Ca m'intéresse. 2002 Oct: No. 260

2. Zannad F, Plétan Y, and the members of the $n^{\circ} 2$ workgroup of Giens. Difficulties in undertaking clinical trials in France. Thérapie 2000; 56: 341-7

3. Le Public et les Essais Cliniques. 10ème Journée de l'Association pour le Développement de la Pharmacologie Clinique, Paris, 22/10/1997. Lettre Pharmacologue 1998; 12 (5): 91-101

4. Law relating to patients' rights and the quality of the health care system, dated 4 March 2002. Bulletin Officiel de la République Française: 5 Mar 2002: article 59-61

5. Law regarding the transposition of two European directives relating to publicity on drugs for human use, homeopathic drugs for human use, medical apparatus, pharmaceuticals and the prevention of smoking. Bulletin Officiel de la République Française: Law no. 94-43, 18 Jan 1994

6. Directive 2001/20/EC of the European Parliament and of the Council of 4 April 2001 on the approximation of the laws, regulations and administrative provisions of the Member States relating to the implementation of good clinical practice in the conduct of clinical trials on medicinal products for human use [online]. Official journal of the European Communities, L121-1/05/2001. Available from URL: http://europa.eu.int/eur-lex/pri/en/oj/dat/2001/1_121/ 1_12120010501en00340044.pdf

7. US Food and Drug Administration. FDA Modernization Act, 1997: section 113 [online]. Available from URL: http://www.fda.gov/opacom/7modact.html [Accessed 2003 Aug 25]

8. Pharmaceutical Research and Manufacturers of America (PhRMA). Principles on conduct of clinical trials and communication of clinical trial results. 2002, 8-e

9. Jaillon P, Detchevery R, Lacondemine H, et al. L'étude d'opinion 10 ans après : 1987-1997. Lettre Pharmacologue 1998; 12 (5): 92-6

10. Autret E, Dutertre JP, Barbier P, et al. Parental opinion about biomedical research in children. Dev Pharmacol Ther 1993; 20: 64-71

11. Benhamou-Jantelet G. Nurses ethical perceptions of health care and medical research: an audit in a French hospital. Nursing Ethics 2001; 8: 2002 
12. Loi portant création de la couverture médicale universelle (CMU). Loi n 99-641 du 27 juillet 1999: article 56

13. Centre d'Investigation Clinique de NANCY (Nancy CIC) [online]. Available from URL: http://www.chu.nancy.fr/CIC

14. Fournie X. Avantages et conditions d'utilisation du contact direct avec les patients dans l'évaluation de la santé. Pro-Clinica (Centre de Contacts et d'Assistance Logistique Médicalisé pour les Études), 2002. (Data on file)

15. French freedom of information and civil liberties act: law relating to files and civil liberties. Law no. 78-17, 6 Jan 1978

16. French freedom of information and civil liberties act: law relating to the treatment of nominative data used in health research. Law no. 94-548, 1 Jul 1994

17. Helsinki Declaration: recommendations to doctors in the field of biomedical research relating to human beings. 52nd General Assembly; 2000 Oct; Edinburgh
18. Chambre Correctionnelle de Paris. Quotation in Le Monde dated 15/09/02. Le Monde 2002 Sept 15

19. Wall Street Journal 2002 Oct 24

20. Gashin A, Ward S. USA Today 2002 Oct 23

21. Appl Clin Trials 2002; 8 Aug

Correspondence and offprints: Faïez Zannad, CIC-INSERM-CHU de Nancy, Hôpital Jeanne d'Arc, 54201 Dommartin les Toul Cedex, France.

E-mail: cic@chu-nancy.fr 